\title{
JOURNAL.RU
}

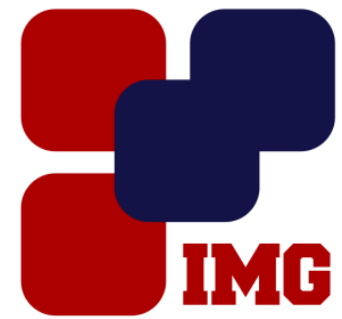

IVAnov
MaNAGEMENT
GROUP

Черникова Т.А., Варисов А.3. Бирский филиал Баикирского государственного университета Бирск, Россия

doi: $10.18411 / 1 \mathrm{j}-31-05-2017-33$

idsp 000001:1j-31-05-2017-33

\section{Формирование исследовательских компетенций будущих бакалавров педагогики}

\section{Аннотация}

Совершенствование образования требует исследовательского отношения педагога. В процессе обучения в вузе студентам необходимо овладеть исследовательскими компетенциями. Для формирования готовности к реализации исследовательской деятельности значение имеют понимание её сущности и структурных компонентов, комплексный подход.

Ключевые слова: профессиональное саморазвитие, исследовательская деятельность, исследовательские компетенции, готовность к исследовательской деятельности, виды исследовательской деятельности студентов.

Инновационные процессы, внедрение в практику новых образовательных технологий требуют творческого, исследовательского отношения со стороны педагога к своему труду. Учитель должен осознавать и уметь самостоятельно формулировать задачи по совершенствованию педагогического процесса, выбирать рациональный способ их решения, планировать и разрабатывать стратегию своей деятельности, анализировать результаты деятельности.

Каждый учитель, творчески относящийся к своей профессии, должен ощущать потребность в проведении исследования и уметь его осуществлять. В.А.Сухомлинский отмечал, что становится мастером педагогического труда, скорее всего тот педагог, кто почувствовал в себе исследователя.

Научно-исследовательская работа должна быть направлена в большей степени на овладение знаниями, умениями и способами продуктивной 
деятельности. С выполнением исследовательской деятельности связано профессиональное становление студентов, самоопределение в выборе решения профессиональных задач.

По мнению А.В.Хуторского [3], исследовательская компетенция носит метапредметный характер по отношению к образовательному процессу и является ключевой по отношению к педагогической деятельности учителя.

Организация исследовательской деятельности предполагает создание условий для освоения обучающимися способов активной самостоятельной познавательной деятельности. Поскольку она осуществляется посредством интеллектуальных и эмоционально-волевых усилий обучающихся, то предполагает раскрытие и учет индивидуальных возможностей и особенностей студента, обладает значительным развивающим потенциалом и может выступать как средство самореализации, самообразования. Включение сначала в учебноисследовательскую, а затем в научно-исследовательскую работу помогает студентам овладеть методами поиска, обработки и использования информации, освоить методы исследовательской деятельности, определиться в своей профессиональной позиции, что помогает развитию профессиональных способностей и творческому отношению к своей профессии. Каждый этап исследовательской деятельности вносит свой вклад в профессиональное развитие студентов.

Определим понятие «готовности к исследовательской деятельности». Это динамично развивающееся качество личности будущего бакалавра педагогики субъекта профессионально-педагогической деятельности, характеризующееся наличием системы мотивов и ценностей, отражающих положительное отношение к научно-исследовательской деятельности, пониманием её роли и цели в деятельности педагога, системы знаний о сущности, методологии и методике осуществления научного исследования, комплекса исследовательских умений и навыков, рефлексивной позиции по отношению к собственной профессиональной и исследовательской деятельности.

Профессиональная готовность будущего бакалавра педагогики к реализации исследовательской деятельности может быть представлена, с нашей точки зрения, следующими взаимосвязанными структурными компонентами: 1) мотивационно-ценностный компонент, выражающий осознанное отношение к исследовательской деятельности и понимание её роли в решении проблем педагогической теории и практики; 2) содержательно-ориентировочный компонент, объединяющий совокупность знаний о сущности исследовательской 
деятельности, требований к её организации; 3) операционно-действенный компонент, основанный на комплексе исследовательских умений и навыков; 4) рефлексивно-оценочный компонент, характеризующий познание и анализ собственной исследовательской деятельности.

Исследовательская деятельность будущего бакалавра педагогики должна обеспечивать формирование профессиональных исследовательских компетенций: готовности использовать систематизированные теоретические и практические знания для постановки и решения исследовательских задач в области образования, способности руководить учебно-исследовательской деятельностью обучающихся. Следовательно, студенты должны освоить методологию педагогического исследования и исследования в области науки по профилю подготовки.

Для этого элементы исследовательской деятельности должны пронизывать изучение курсов профессионального цикла. Это может находить воплощение в освоение отдельных элементов и методов исследовательской деятельности, решении исследовательских задач, выполнение исследовательских работ.

При подготовке будущих учителей физики одним из базовых курсов является «Основы теоретической физики». Целями его изучения наряду с ознакомлением с теоретическими основами, формированием единой физической картины мира являются формирование научного мировоззрения. Среди задач выделены также имеющие значение для формирования исследовательских умений: овладение студентами методологией современной физики, освоение методов моделирования и применения приближённых методов в теоретической физике; методов решения физических задач. Изучение данной дисциплины способствует овладению теоретическими подходами к описанию физических явлений, процессов, решению проблемно-исследовательских задач.

Важную роль играют курсы по выбору. Например, для подготовки будущих учителей физики к компьютерному моделированию физических явлений и процессов предлагается включить в учебный план курсы по выбору: «Моделирование квантовомеханических явлений», «Моделирование стохастических систем». Учитель физики должен владеть информационнокомпьютерными технологиями и на уровне моделирования физических явлений и процессов. Это особенно актуально в работе с одаренными учащимися, ориентированными на углубленное изучение дисциплин естественноматематического профиля и нацеленных на участие в исследовательской деятельности уже в школе. Изучение данных курсов по выбору призвано не 
только продемонстрировать роль численных методов при решении квантовомеханических и статистических задач с применением информационных и компьютерных технологий, но и помочь будущему учителю физики освоить методологию компьютерного моделирования в физике как исследовательскую технологию.

Требования к результатам изучения данных курсов по выбору могут быть дополнены специальными компетенциями: владение навыками организации и постановки физического эксперимента (лабораторного, демонстрационного, компьютерного); владение методами теоретического анализа результатов наблюдений и экспериментов, приемами компьютерного моделирования.

Изучение курса «Педагогика» предполагает освоение студентами методологии, методики научно-педагогического исследования, проведения педагогического эксперимента. Современному учителю это поможет в разработке, апробации и внедрение инноваций в образовательный процесс.

Задания к педагогической практике также должны содержать научноисследовательскую составляющую: анализ опыта учителей, изучение учебнопознавательной деятельности учащихся, внедрение элементов инноваций в практику, организация исследовательской деятельности учащихся и др.

Для педагога овладение исследовательскими умениями имеет особое значение: современные требования к обучению учащихся ориентированы на их самостоятельную и исследовательскую деятельность, что требует, чтобы сам педагог владел такой деятельностью; совершенствование обучения требует постоянного обновления приемов, средств и форм обучения, поэтому учитель должен уметь их конструировать, модернизировать имеющиеся.

Для выполнения работ научно-исследовательского характера на начальном этапе студентам может предлагаться алгоритм: 1) знакомство с темой научноисследовательской работы; 2) поиск научно-методической литературы по проблеме, корректировка темы; 3) обоснование актуальности темы, составления плана работы; 4) определение объекта и предмета исследования; 5) постановка цели и задачи работы, формулировка гипотезы; 6) определение методов исследования; 7) анализ литературы по проблеме, отбор необходимой информации; 8) привлечение опытных данных, полученных в период педпрактики; 9) обобщение собранного материала, формулировка выводов, оформление работы; 10) подготовка доклада, презентации.

В вузе исследовательская деятельность должна выступать и как одна из активных технологий обучения. Например, Бордовский Г.А. в качестве 
современной модели образования выделяет проектно-исследовательскую. Это модель «обучения посредством действия», которая предполагает, что студенты работают над реальными задачами, а не над искусственными ситуациями, учатся не только у преподавателя, но и в процессе анализа реальных проблем, участвуя в их исследовании и обсуждении полученных решений, работают с различными базами информации для выбора и принятия решений в контексте реальных ситуаций, учатся мыслить критически и принимать ответственность за выбор решения [2].

При формировании исследовательских компетенций студентов необходимо включать их в исследовательскую деятельность не только на учебных занятиях. Важно учитывать два вида исследовательской деятельности студентов в вузе [1]: встроенная в учебный процесс в рамках учебного плана (в этом случае ее принято называть учебно-исследовательской деятельностью) и выходящая за пределы учебного процесса (этот вид деятельности обычно называют научно-исследовательской). Научно-исследовательская деятельность организуется в рамках научно-исследовательских семинаров, кружков, подготовки публикаций по итогам выполнения курсовых работ, выпускных квалификационных работ, творческих проектов.

Таким образом, процесс формирования исследовательских компетенций будущих бакалавров педагогики может быть эффективным при комплексном подходе. Он предполагает обучение исследовательской деятельности в процессе изучения базовых профессиональных дисциплин, курсов по выбору, практики, внеучебной деятельности, в процессе применения исследовательских технологий обучения. При этом выполнение студентами исследовательской работы позволяет развивать положительную мотивацию на самостоятельную исследовательскую деятельность, стимулирует профессиональное саморазвитие в целом. Необходима системная подготовка студента к научноисследовательской деятельности как составляющей будущей профессиональной деятельности, так и механизма, обеспечивающего саморазвитие в профессиональном плане. 
1. Алексанова Г. Т., Алексанова С. А. Формирование исследовательской компетенции у студентов вуза в условиях перехода на новые стандарты обучения // Научнометодический электронный журнал «Концепт». - 2016. - № S3. - C. 1-5. - URL: http://ekoncept.ru/2016/76028.htm. (дата обращения 4.05.2017)

2. Бордовский Г.А. Особенности развития современного педагогического образования // Педагогика. - 2010. - № 5. - С. 59-66.

3. Хуторской А. В. Ключевые компетенции как результат личностно-ориентированной парадигмы образования // Народное образование. - 2003. - № 2. - С. 58-64. 